\title{
Administrando la Comunicación de Riesgos en una Emergencia Sanitaria, "El caso de la erupción del Volcán Calbuco", Chile 2015 \\ Managing the Risk Communication in a Health Emergency, "The case of the eruption of the Calbuco Volcano", Chile 2015
}

\author{
Leonardo Díaz Bouquillarda \\ a Departamento de Comunicaciones, Secretaría Regional Ministerial de Salud, Chile
}

\section{Resumen}

El siguiente trabajo presenta la estrategia comunicacional desarrollada por la institución Seremi de Salud, durante la emergencia sanitaria por la erupción del Volcán Calbuco (Región de Los Lagos, Chile) en abril del 2015, para disminuir los riesgos en la salud de las personas y comunidades expuestas a la erupción. Se da cuenta de una estrategia preventiva e informativa a través de diversos materiales, incluyendo las redes sociales, además de la transparencia institucional en términos de información a la comunidad sobre calidad del aire, agua y ceniza. El análisis de las redes sociales institucionales (twitter) indica que los ejes discursivos sanitarios fueron adecuadamente apropiados y difundidos por la comunidad.

Palabras clave: Salud pública; Comunicación de riesgos; Redes sociales en salud; Vigilancia ambiental; Vigilancia epidemiológica.

\begin{abstract}
The following work presents the communicational strategy developed by the Health Seremi institution, during the health emergency due to the eruption of the Calbuco Volcano (Los Lagos Region, Chile) in April 2015 , to diminish the risks of health for people and communities exposed to the eruption. A preventive and informative strategy was reported through various resources, including website social networks, as well as institutional transparency in terms of information towards the community regarding air quality, water and ash presence. The analysis of institutional social networks (twitter) indicates that the sanitary discursive cores were properly fitting and spread in this social network.
\end{abstract}

Keywords: Public health; Risk communication; Health social network; Environmental monitoring; Epidemiological surveillance. 


\section{Introducción}

E I miércoles 22 de abril del 2015, a partir de las 18.00 hrs., aproximadas, inicia un ciclo eruptivo el Volcán Calbuco, macizo cordillerano de más de 2 mil metros de altura, ubicado al sur de Chile y específicamente en la región de Los Lagos. Ubicado a 30 kilómetros de importantes comunas como Puerto Montt y Puerto Varas, el Volcán Calbuco, es un gigante rodeado por pequeños poblados como Ensenada, Correntoso, Río Blanco, Colonia Sur y Alerce, los cuales se encuentran en su área de impacto.

Es un macizo gigante de $95 \mathrm{Km} 3$ y un área basal de $180 \mathrm{Km} 3$, el cual puede ser observado a más de $100 \mathrm{ki}-$ lómetros de distancia. Es un volcán imponente, qué duda cabe, parte importante del paisaje habitual para los habitantes de la región de Los Lagos y turistas.

Se tiene data de al menos 12 ciclos eruptivos históricos de este volcán. Debido a su composición andesítica predominante, las erupciones históricas revelan un comportamiento eruptivo violento, caracterizado por eyección de piroclastos de caída y de flujo, además de lavas, domos, espinas, oleadas por explosión lateral y lahares (Ficha Volcán Calbuco, www.sernageomin.cl/volcan-calbuco).

De acuerdo a los datos del Servicio Nacional de Minería y Geología, Sernageomin, los flujos piroclásticos históricos han afectado principalmente el sector noreste del volcán y en menor medida hacia el lago Chapo. La erupción histórica más importante ocurrió en 1893-95, a partir de la cual, se comenzó a formar el domo que ha crecido hasta alcanzar el borde del escarpe originado por la avalancha. Antes de erupciones de cierta magnitud, han ocurrido precursores tales como ruidos subterráneos, sismos, fumarolas y pequeñas explosiones de ceniza (http://www.sernageomin.cl/volcan-calbuco/).

La activación o reactivación de un volcán es uno de los fenómenos naturales más temidos y respetados. Es que su acción transformadora de la geomorfología del paisaje y sus efectos en la salud pública, hacen de las erupciones volcánicas un proceso complejo para las poblaciones que están influenciadas por su acción (Organización Panamericana de la Salud [OPS], 2005).

A diferencia de otros desastres naturales, las erupciones volcánicas se presentan con diferentes episodios en un lapso indeterminado de tiempo y con magnitud variable, podríamos afirmar entonces que las erupciones volcánicas, son ciertamente un verdadero "subgénero": guardan códigos, lenguajes, imágenes, una iconografía, además de historias e incluso muchas veces un relato común en torno a un proceso eruptivo (que puede ser de días, meses e incluso años). En otras palabras: es un fenómeno único, que debe abordarse con su complejidad e individualidad.

La OPS señala que desde el punto de vista de la salud, los efectos más comunes causados por las erupciones volcánicas incluyen lesiones traumáticas, quemaduras, asfixia, enfermedades en la piel, lesiones oculares, problemas respiratorios, conjuntivitis y hasta la muerte. Particularmente, la caída de ceniza o expulsión de gases, generan riesgo de contaminación del agua y de los alimentos, así como la afectación del ganado y animales domésticos, de cultivos y en general del medio ambiente, comprometiendo también los servicios básicos (agua, transporte, comunicaciones) y el acceso a los servicios de salud (www.paho.org/disasters).

Igualmente, el cúmulo de cenizas sobre techos o cubiertas puede causar daños o colapso de edificaciones, tanto de forma inmediata como posterior al evento, como en la fase de limpieza. Esto ha generado la ocurrencia de accidentes con politraumatismo por el colapso de los techos, por ejemplo.

\section{El inicio del Pulso Eruptivo y la Estrategia Comunicacional}

El Observatorio Volcanológico de los Andes del Sur (OVDAS) informaba en su reporte del día 22 de abril emitido a las 17.30 hrs, que el Volcán Calbuco había iniciado una sismicidad y un enjambre sísmico asociado a ruptura de material rígido, desde las 15.11 horas. Un par de horas más tarde, dicho enjambre se convertía en un nuevo pulso eruptivo del macizo Calbuco.

En efecto, a partir de las 18.00 horas de aquel día, la región de Los Lagos nuevamente estaba en el centro de la agenda noticiosa, el gigante Calbuco inicia "actividad eruptiva (en su fase más energética) la cual se prolongó por 1 hora y 30 minutos, desarrollando una columna eruptiva que alcanzó unos $15 \mathrm{~km}$ por sobre el cráter principal con un penacho dirigido hacia el $\mathrm{N}$ y $\mathrm{E}$, registrando a la hora de emisión de este informe, valores moderados de sismicidad cercanos al ruido de fondo" (Reporte Especial Actividad Volcánica, REAV, 2015).

Señala un nuevo informe (emitido a las $22.30 \mathrm{hrs}$ ), "La dispersión piroclástica en la atmósfera ha sido esencialmente hacia el $\mathrm{N}$ y $\mathrm{E}$ del volcán. Sin embargo, la ceniza fina en suspensión está siendo transportada hacia el $\mathrm{N}$ y NW pudiendo alcanzar las regiones de Los Ríos, Araucanía y Bío-Bío en las próximas horas. Es esperable caída de ceniza fina de espesores milimétricos. En las condiciones actuales, el área proximal susceptible de ser afectada puede reducirse al radio interno de 10 km" (REAV, 2015). 


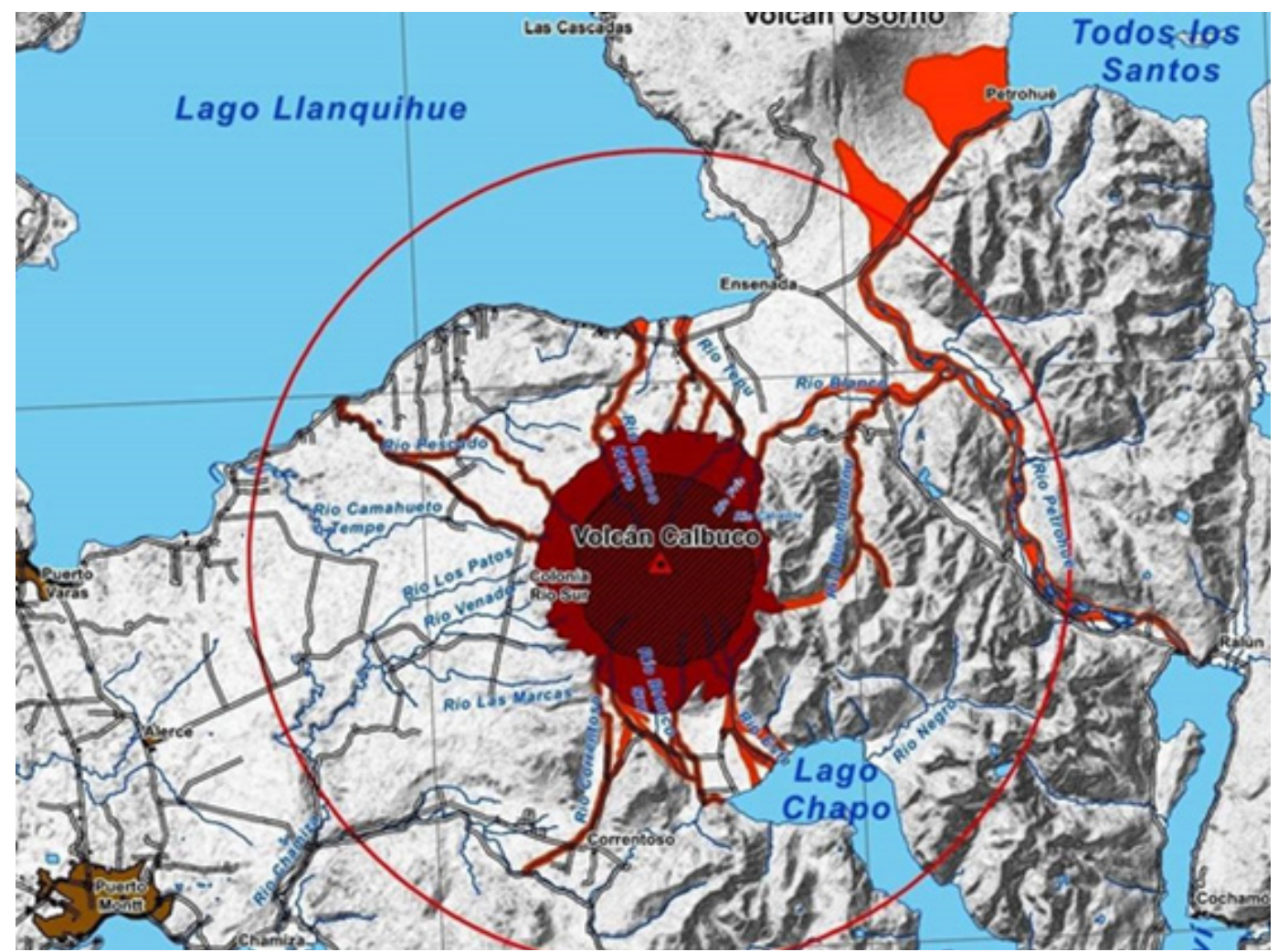

Figura 1. Mapa área afectada erupción Volcán Calbuco

Aunque esta actividad volcánica no causó muertes de manera directa, propició la evacuación de 6 mil personas de las cuales 307 fueron establecidas en albergues autorizados. Como institución de salud se inició la vigilancia epidemiológica y ambiental en 2 ámbitos: Vigilancia epidemiológica de enfermedades trazadoras, esto es, infecciones respiratorias, infecciones oculares conjuntivales, lesiones de la piel, trastornos psicológicos, enfermedades crónicas descompensadas y Vigilancia ambiental, esto es, monitoreo de ceniza, monitoreo de calidad del aire y monitoreo en calidad del agua.

Ciertamente, los eventos volcánicos implican una situación de crisis para las organizaciones y las comunidades, puesto que alteran las relaciones cotidianas y el entorno al cual están habituadas, "lo que provoca un considerable incremento en la demanda y en la necesidad de información de las organizaciones, los medios de comunicación y las comunidades" (OPS, 2005).

Esta demanda informativa la afrontamos a través de una estrategia comunicacional que tuvo como objetivo: minimizar el impacto en la salud de las personas, derivadas de la erupción del volcán Calbuco en el ámbito médico y sanitario ambiental. Nuestro público objetivo se concentró en los habitantes de la Provincia de Llanquihue y con especial atención a las comunas de Puerto Montt y Puerto Varas, además de las personas afectadas directamente, evidentemente.

Para ello desplegamos un trabajo a través de diversas fases, entendiendo que una emergencia sanitaria como una erupción volcánica, es una narración, la cual se inicia a través de una "proto imagen" violenta, potente, espectacular e icónica.
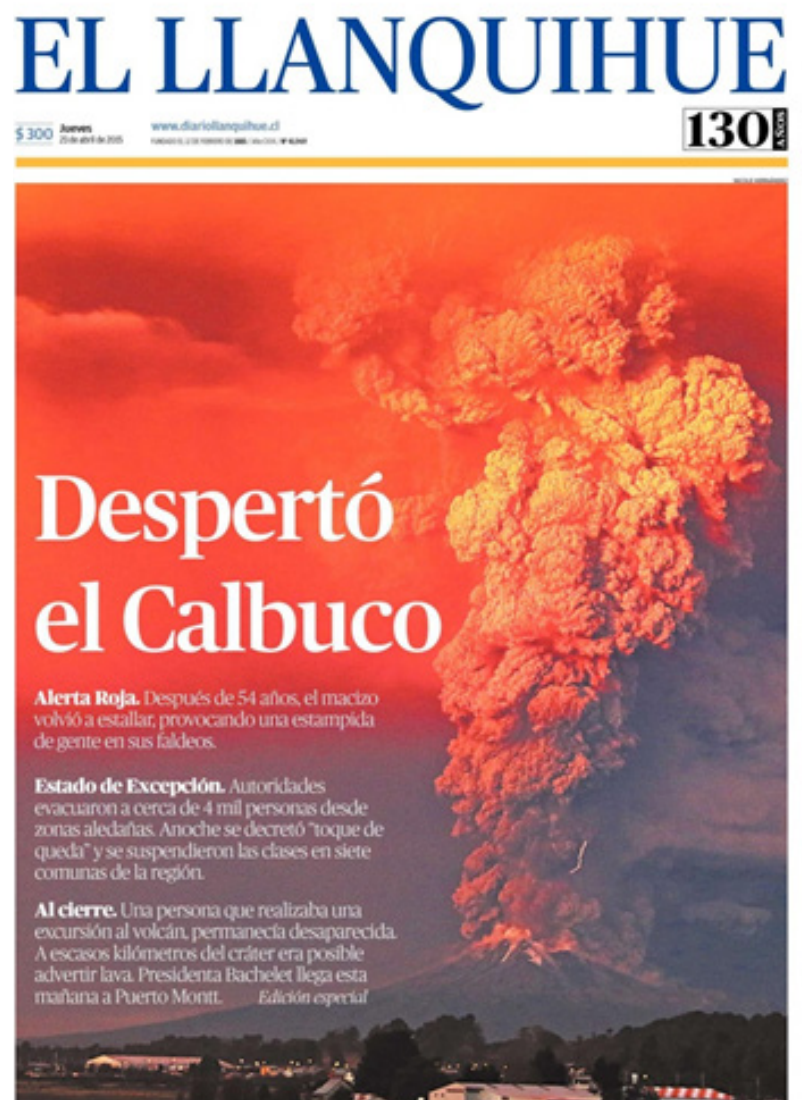

Figura 2: Portada Diario El Llanquihue con la espectacularización de la erupción. 
Si bien establecemos fases de trabajo, el dinamismo propio de una emergencia hace que los límites de las fases se superpongan también.

Etapa 1: Fase eruptiva: Etapa orientada al control de daños que pudiesen haber ocurrido desde la atención en salud, a través de la verificación de lesiones, traumas etc. También se monitorean las condiciones sanitarias de la red asistencial quienes deben entregar atención médica a las personas. Además se realiza un catastro de las condiciones sanitarias de los albergues, donde se estima será trasladada la población afectada.

El énfasis comunicacional es en términos de emergencia e inmediatez, por eso se realiza a través de diversas infografías difundidas en redes sociales y con mensajes radiales entregando recomendaciones básicas sobre salud en condición de emergencia.

Se trata de mensajes para minimizar el impacto derivado de la ceniza volcánica en 3 temas prioritarios: aparato respiratorio, protección ocular y protección dermatológica, sugiriendo utilización de pañuelos húmedos, permanecer en ambientes cerrados, lavado abundante con agua si se exponen los ojos a la ceniza.

Paralelamente se refuerza la vigilancia epidemiológica de las enfermedades "trazadoras", es decir, aquellas que nos indican aumento o disminución de afecciones derivadas de una emergencia. Se vigila el aumento de enfermedades respiratorias, salud mental, entre otras.

Etapa 2: Fase post eruptiva (y de transparencia): Se refiere al monitoreo de las personas, que ya están en los albergues. Desde una perspectiva sanitaria y de salud mental, se hace vigilancia a su condición de salud. En situaciones de hacinamiento emergen ciertos cuadros que deben ser monitoreados, para ello, se realizan mensajes específicos para esta población sobre las condiciones de habitabilidad en los albergues (OPS, 2005).

Comunicacionalmente, el énfasis está puesto en elaboración de mensajes sanitarios orientados al control ambiental para el consumo de agua en forma segura, con especial atención a los sistemas de Agua Potable Rural. Se recomienda consumir un agua clara y transparente, sin turbiedad. Y en caso de dudas, filtrarla y hervirla. Además se refuerza recomendaciones por enfermedades que pueden emerger en un proceso post eruptivo, como por ejemplo, el hanta virus, por el desplazamiento de los roedores, propios de los sectores rurales aledaños al volcán.

En esta etapa se hace muy necesaria, por parte de la población afectada y los medios de comunicación, conocer la información de los análisis de monitoreo tanto del aire como del agua. Por ello todo el muestreo sanitario realizado se transparenta en página web institucional www.seremisaludloslagos.cl y también a través de partes de prensa, enviados diariamente. El objetivo es bajar la ansiedad natural, incertidumbre y el miedo que puede generar en la población no contar con información. Hay que tener en cuenta que en una situación de crisis aumenta el número de fuentes que pueden trasladar mensajes a la población, que pueden llevar multiplicidad de mensajes. Si no eres tú quien informa, otro lo hará por ti, puesto que hay mucha demanda de información (Rodríguez, 2011).

Etapa 3: Fase de re instalación: Se refiere el mejoramiento de las condiciones de seguridad de ciertos sectores amagados y la reinstalación de las personas afectadas en sus hogares, para ello se deben enviar mensajes sanitarios orientados al consumo de alimentos seguros, limpieza del hogar (ceniza), hanta virus, condiciones sanitarias generales (estanques), que faciliten la reinstalación sin mayores riesgos.
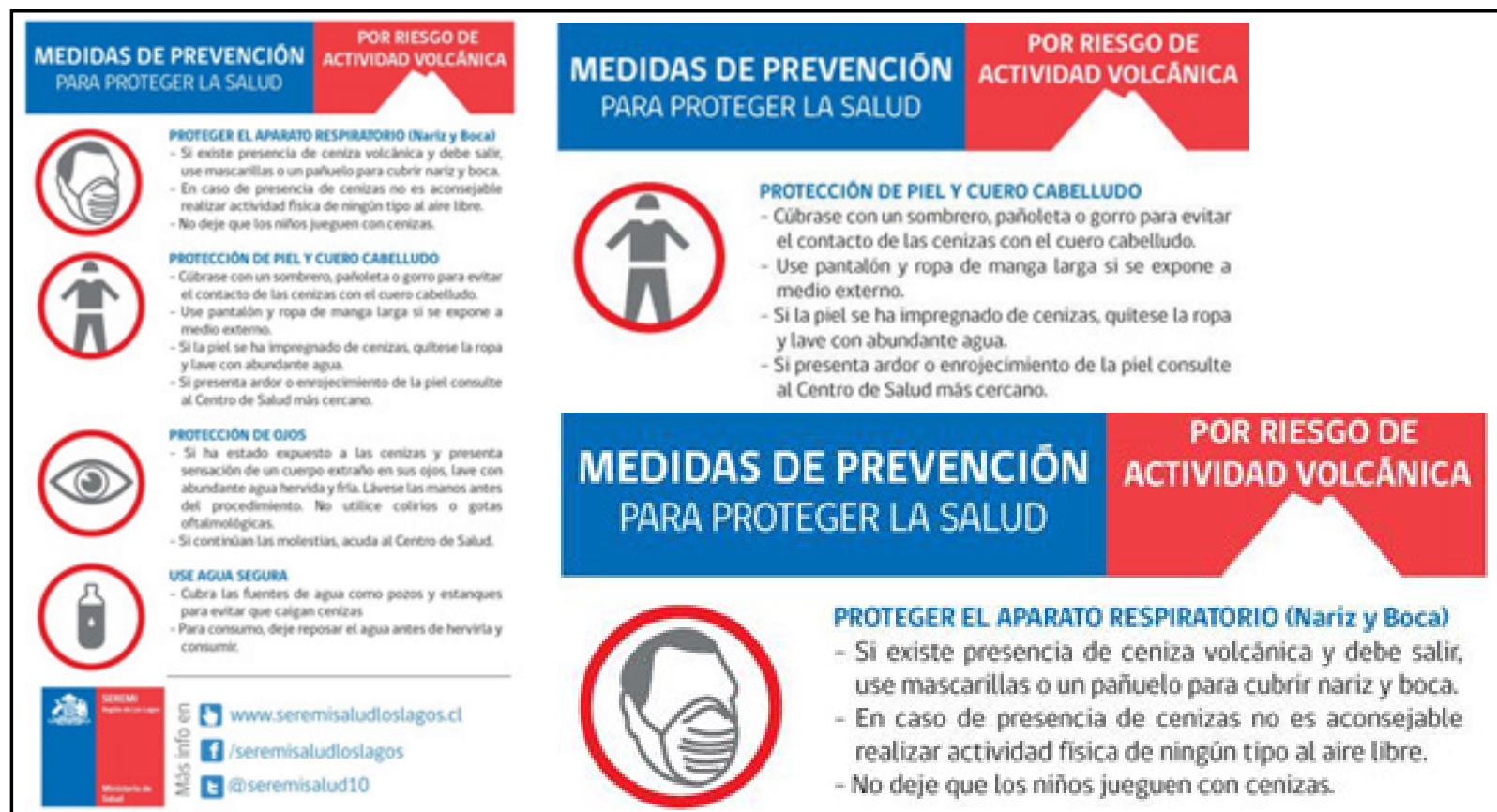

PROTEGER EL APARATO RESPIRATORIO (Nariz y Boca) - Si existe presencia de ceniza volcánica y debe salir, use mascarillas o un pañuelo para cubrir nariz y boca. - En caso de presencia de cenizas no es aconsejable realizar actividad fisica de ningún tipo al aire libre. - No deje que los niños jueguen con cenizas.

Figura 3. Material gráfico utilizado durante la emergencia. 


\section{Las Redes Sociales en este Evento: Metodología para un Análisis}

Es un hecho generalizado que el desarrollo de la web 2.0 ha cambiado sustancialmente la forma en que conviven y se comunican las personas. Con la irrupción de la web hemos pasado de ser un receptor pasivo a un usuario participativo y co creador de contenidos. La aparición de diferentes dispositivos y de múltiples aplicaciones que hacen posible esta interacción, es otra de las claves en las que se basa esta nueva realidad (Fernández-Gómez y Díaz-Campos, 2016).

La comunicación sobre la salud no es una excepción a esta tendencia y el uso de las redes sociales en este sector es cada vez mayor. La gestión de las crisis sanitarias conlleva una gran complejidad puesto que la comunicación sanitaria ya no es unidireccional, sino multidireccional (Guzmán do Nascimento, 2018).

Tal como lo dice el Manual de Herramientas para el uso de redes sociales del Centro para el Tratamiento de las Enfermedades (CDC), las redes sociales en salud pueden permitir conectar a millones de personas incrementando el tiempo en la difusión de medidas de protección de la salud, personalizar y reforzar mensajes de salud, facilitar la interacción de los usuarios y empoderar a la población a que tome decisiones saludables (CDC, 2011).

Desde el punto de vista metodológico buscamos analizar los contenidos emitidos por la institución de salud específicamente en su cuenta de twitter @seremisalud10 durante el 22 de abril y 27 de mayo, es decir, un poco más de 1 mes, tras la erupción.

Proponemos conocer si los mensajes entregados son coherentes con la cronología propia de la erupción, así como el promedio de mensajes emitidos durante la emergencia y sus principales características y contenidos: ¿se trata de mensajes preventivos, informativos o de gestión en terreno? De igual manera, describimos si estos mensajes utilizan recursos audiovisuales, de audio o enlaces. Desde el punto de vista de la interacción con el usuario de la web 2.0 analizamos cuáles son los mensajes con mayor interacción y mayor viralización, en este ecosistema web, dónde la pregunta parece ser ¿cómo comunicamos la emergencia del Volcán Calbuco?

\section{Algunos Resultados}

La muestra analizada está compuesta por un total de 134 mensajes emitidos por la cuenta de la Seremi de Salud durante la emergencia, en su red social de twitter, esto desde el 22 de abril al 27 de mayo, es decir en un marco de 36 días. El promedio de publicaciones fue de 3,7 mensajes emitidos por día, sin embargo hay que destacar que la cronología de publicaciones es más intensa durante los primeros 9 días de la emergencia (gráfico 1).

Desde el punto de vista de la evolución de los mensajes emitidos por la institución se observa un peak los primeros 2 días de la emergencia, esto es el 22 y 23 de abril con 11 y 12 mensajes respectivamente y posteriormente los días 28 y 29 de abril, con 17 y 14 mensajes emitidos respectivamente.

El 2 do peak de emisión de mensajes ( 28 y 29 de abril), tiene relación con la visita en terreno de autoridades de salud nacionales quienes haciendo "gestión en terreno", visitan las principales zonas afectadas, lo que implicó el reforzamiento de medidas preventivas, por ejemplo a través de la vacunación contra influenza a personas afectadas.

Asimismo, es importante destacar que desde el 2 de mayo existe una disminución considerable en la emisión de mensajes, rompiendo la tendencia el 4 de mayo con 9 mensajes que tienen su correlato con la necesidad informativa por parte de la comunidad: conocer la calidad del agua en sectores rurales como Cochamó, Lago Chapo y Ensenada.

La tendencia a la baja se hace más patente; de hecho, con fecha 9 y 10 de mayo, no existe emisión de contenido por parte de la red social. Es así como el 14 de mayo es el último día en que se publica información relativa al Volcán Calbuco, para luego retomarla el 27 de mayo, con 3 mensajes que aluden a la entrega de los "kit preventivos" de hanta virus a las comunidades de Lago Chapo, esto se relaciona a un primer "cierre" narrativo relativo a la emergencia, al hacer entrega de un kit de prevención a las familias que están regresando a sus viviendas a 1 mes de la erupción, en la Etapa 3 de re instalación.

Respecto a la descripción de los mensajes emitidos durante la emergencia, 50 de ellos corresponden a gestión en terreno, esto es, las autoridades de salud regionales y nacionales, enfrentando la emergencia tanto en reuniones informativas con la comunidad, visita a albergues con los afectados, así como en acciones técnicas propias de la toma de muestras para los análisis de elementos como aire y ceniza.

Por su parte, 46 mensajes corresponden a información preventiva a la comunidad en relación a la protección de elementos como la ceniza, el manejo del agua, prevención ocular, respiratoria y del hanta virus. Se trata de recomendaciones netamente preventivas en dichos ámbitos y que tienen su principal foco de acción los primeros 9 días de la emergencia. Se desprende también del análi- 
sis que los mensajes emitidos con mayor frecuencia se remiten a la protección derivada de la ceniza volcánica (protección respiratoria, ocular, dermatológica) a través de 25 mensajes.

Finalmente, los otros 38 mensajes los hemos seleccionado en la categoría "informativa", se trata de difusión que da cuenta, en un ejercicio de transparencia, de los resultados en los análisis efectuados a la ceniza, aire y agua. Además, en esta categoría también se incorporan las notas de prensa que van reproduciendo y difundiendo las acciones propias de la institución para enfrentar la emergencia.

Estos mensajes corresponden a la Etapa 2 de la emergencia, cuando la necesidad de información sobre la calidad de elementos primarios es altamente demandada.

Respecto a la descripción de los contenidos, a través de la red social, a partir del primer día la institución de salud utiliza el hashtag \#VolcanCalbuco incorporando info- grafías para referirse a ámbitos de prevención. La incorporación de elementos multimedias es escasa, remitiéndose solamente a audios con medidas preventivas que no tienen mayor impacto.

Desde el punto de vista de la recepción (Ver gráfico 2) la gestión de la crisis tuvo una importante cantidad de retroalimentación a través de la red social. En efecto, durante los primeros 9 días de la emergencia se emiten una cantidad de 92 mensajes con una réplica de 755 retweet, alcanzando la mayor cantidad el primer día de la emergencia con 258 interacciones.

El twitter con mayor número de interacciones, se refiere al mensaje emitido el 24 de abril sobre prevención ante el aumento de ceniza con 88 retweet. Asimismo, con fecha 13 de mayo se produce un total de 38 retweets por parte de los usuarios, esta acción tiene relación a una primera entrega de un kit preventivo para el hanta virus a una de las comunidades afectadas que regresan a habitar sus viviendas.

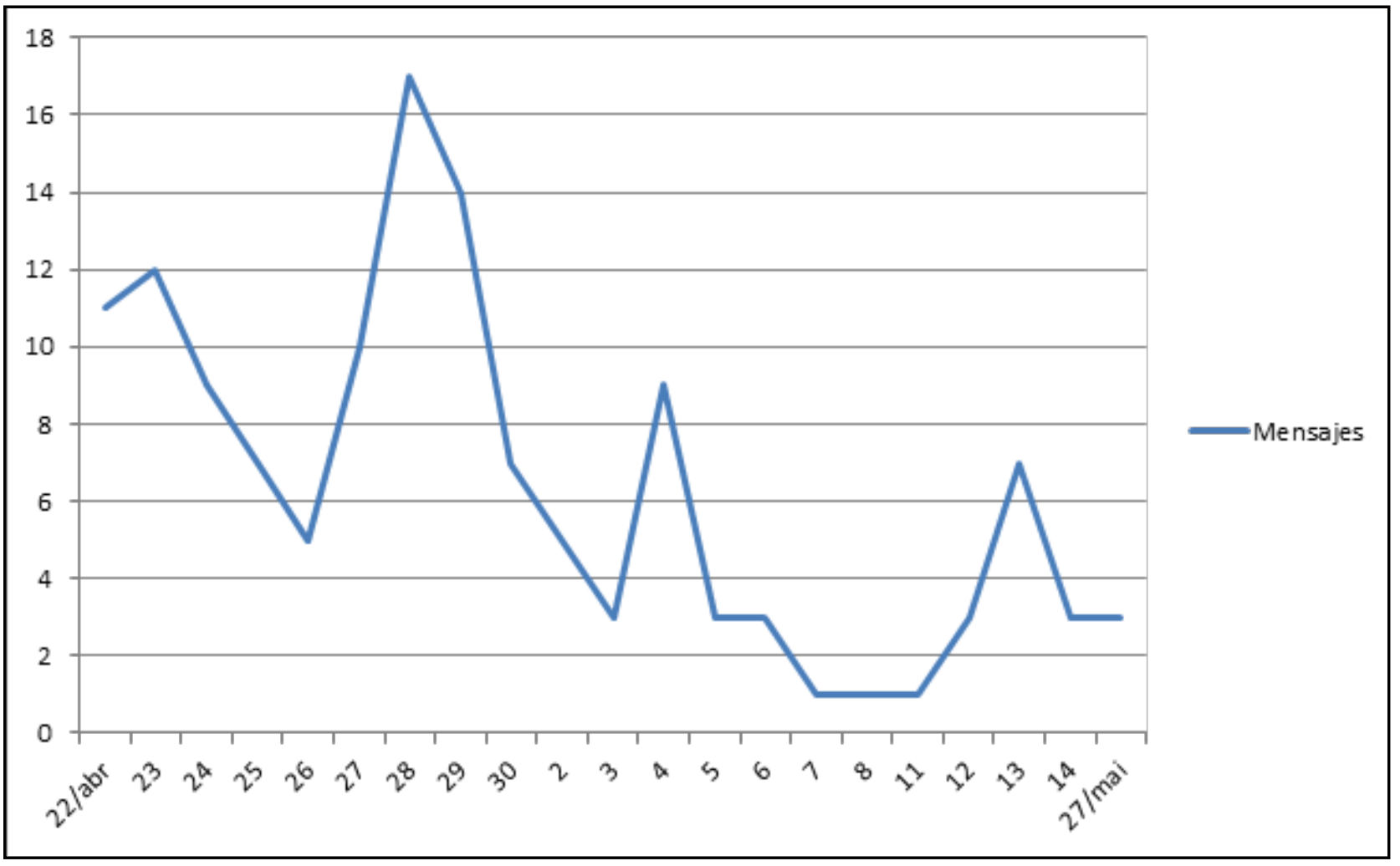

Gráfico .Promedio de publicaciones emitidos por la cuenta @seremisalud10 en twitter. 


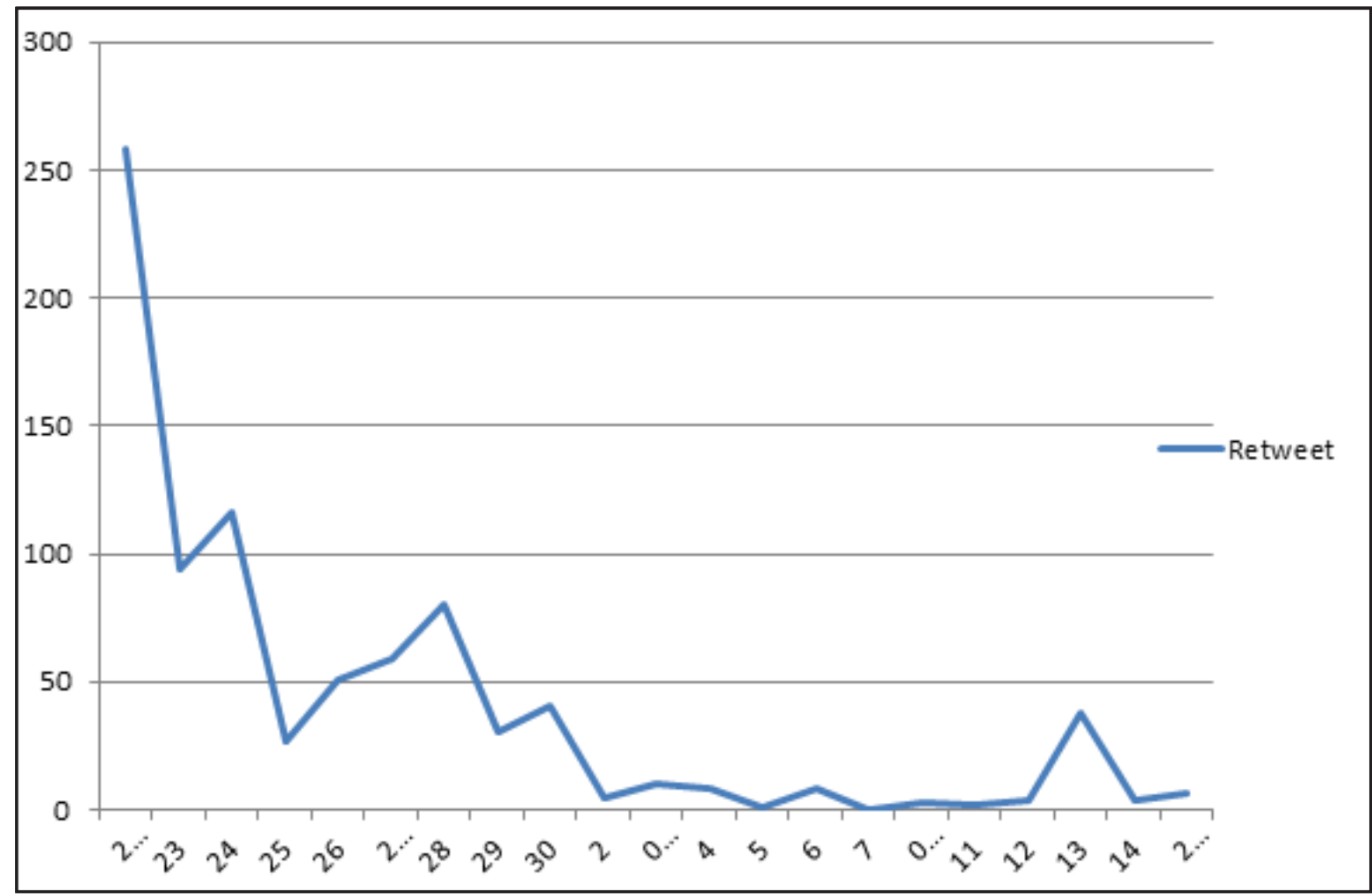

Gráfico . Número de interacciones de usuarios con la cuenta de twitter.

\section{Conclusiones de una emergencia Volcánica}

Las características geográficas de Chile implican que todo su territorio esté expuesto a amenazas de desastres de diversa índole. Estas particularidades geográficas, conjugadas con la demografía del país, junto a diversos aspectos sociales, políticos y económicos, configuran el riesgo de desastres que exponen a la población, la infraestructura y los sistemas a sufrir importantes pérdidas y vulnerabilidades, tanto en términos de vidas humanas como en aspectos económicos, medioambientales, físicos, emocionales y sociales (Ministerio de Salud, 2017).

La emergencia del Volcán Calbuco configuró una respuesta del sector salud como de la comunidad muy positiva y adecuada que este documento busca poner en valor.

En efecto, el informe de las acciones realizadas por la institución de salud (desde el 22 de abril al 22 de mayo) da cuenta de un análisis acumulado de 17215 atenciones en los diversos centros de salud implementados con vigilancia de enfermedades trazadoras, destacando que durante la emergencia tuvieron predominancia las enfermedades causadas por "otras causas no asociadas al volcán, especialmente en el rango de 15 - 59 años".

Se puede deducir a través de los análisis continuos hasta el 22 de mayo que la mayor parte de las consultas fueron por infecciones respiratorias altas (asma, bronquitis, rinofaringitis), no asociadas al volcán y especialmente en el rango de población menor de 59 años con predominancia de sexo femenino.
Desde el punto de vista ambiental se realizan 500 muestreos de agua para conocer la calidad de fuentes de agua potable y no potable para consumo humano, en términos bactereológicos y físicoquimicos, analizando parámetros en cobre, hierro, manganeso, magnesio, turbiedad, ph, de acuerdo a Norma Chilena NCh 409/2. Se analizan un total de 6500 muestras, donde los resultados obtenidos de arsénico se mantienen bajo la normativa (0,01 mg/tt), sin embargo se observa muestras con presencia de coliformes totales y $\mathrm{E}$. coli, en abastecimientos precarios, sin sistema de tratamiento, lo que no tiene relación con la erupción volcánica.

Se realizaron mediciones de calidad de aire para material particulado, sílice y arsénico respirable, durante 6 periodos, de los cuales 2 días se superó la norma vigente, debido a la gran presencia de cenizas en suspensión proveniente de la pluma volcánica. Los niveles de arsénico y sílice se encontraban bajo la norma internacional aplicada para el riesgo a la salud de la población.

En relación a la ceniza se realizaron 11 muestreos de ceniza, en diversos sectores afectados, estableciéndose condiciones normales. Se priorizan los elementos metales que son potencialmente dañinos a la salud humana, como $\mathrm{Cromo}(\mathrm{Cr})$, Níquel (Ni), Arsénico (As), Cadmio (Cd) y Plomo (Pb).

Todo este actuar institucional, que no es más que la respuesta del sector salud ante la emergencia, tuvo un correcto correlato a través de una estrategia comunicacional que fijó parte de su narración en la red social de 
twitter como un tremendo aliado. En efecto, aprehendemos que en esta emergencia volcánica son los primeros días los más intensos en relación a interacción y viralización de las medidas preventivas: 468 retweets los primeros 3 días de la emergencia dan cuenta de aquella necesidad de compartir y viralizar medidas de prevención con especial atención a los efectos inmediatos en la salud de la ceniza volcánica.

Una cronología de acciones a través de la plataforma social que se fue diversificando a través de las tres Etapas definidas en la estrategia y una narración que parte con una espectacularidad icónica (la explosión) para finaliza con la entrega de un kit de prevención para que la comunidad vuelva a habitar su hogar.

De igual manera, llama la atención que la mayor cantidad de mensajes institucionales a través de la plataforma twitter tengan relación con la "gestión en terreno", esto es, la gobernanza de la institución para hacer frente a la emergencia, ¿Debería ser mayor la gestión en terreno a la información preventiva? Ciertamente que en una emergencia de esta magnitud se exige mucho contacto con las comunidades afectadas.

Lo que años atrás parecería una ilusión para los comunicadores en emergencias ambientales, hoy es una realidad, es que las redes sociales y una plataforma como twitter son un aliado necesario para administrar una crisis. La manera en que una epidemia es relatada a través de las redes sociales tiene serias implicancias en su percepción y evaluación social (Guzmán de Nascimento, 2018).

"Mitigar los efectos en la morbi-mortalidad de la población como consecuencia de emergencias, desastres y epidemias", es el objetivo $N^{\circ} 9$ de la Estrategia Nacional de Salud 2011 - 2020, del Ministerio de Salud en Chile, un objetivo que ciertamente debe considerar adecuadas formas de administrar una emergencia con herramientas comunicacionales modernas y que puedan ser correctamente apropiadas por la población.

\section{Referencias Bibliográficas}

Centers for Disease Control and Prevention. (2011). The Health Communicator's Social Media Toolkit. USA: CDC.

Fernández-Gómez, E., y Díaz-Campo, J. (2016). Comunicación sobre el cáncer en Facebook. Las asociaciones de Argentina, Chile, Colombia y España. Cuadernos. Info Comunicación y Medios en Iberoamérica, 38. doi: 10.7764/cdi.38.926

Guzmán do Nascimento, B. (2018). Comunicación y salud: La gestión de la crisis del Ebola a través de las redes sociales. Revista Española de Comunicación en Salud, 9(2), 196-202.

Ministerio de Salud. (2017). Apuntes sobre gestión de riesgo en emergencias y desastres. Chile: Departamento de Gestión de Riesgo en Emergencias y Desastres, Ministerio de Salud.

Observatorio Volcanológico de los Andes del Sur. (2015). Reporte de Situación: Volcán Calbuco 22 y 23 de abril. Chile: Servicio Nacional de Geología y Minería.

Organización Panamericana de la Salud. (2005). Guía de preparativos de salud ante erupciones volcánicas, Modulo 1: El sector salud frente al riesgo volcánico. Ecuador: OPS.

Organización Panamericana de la Salud. (2005). Guía de preparativos de salud ante erupciones volcánicas, Modulo 5: La comunicación frente a erupciones volcánicas. Ecuador: OPS.

Rodríguez, R. (2011). La efectividad del uso del miedo como factor persuasivo en la comunicación de riesgos en las crisis sanitarias. Revista de Comunicación y Salud, 1(2), 33-46.

Sernageomin, Ficha Volcán Calbuco en http:// www.sernageomin.cl/wp-content/uploads/2017/11/3_ Calbuco.pdf 